\title{
Sudden Sensorineural Hearing Loss Due to Drug Abuse
}

\author{
Ivan A. Lopez, Ph.D., ${ }^{1}$ Akira Ishiyama, M.D., ${ }^{1}$ and Gail Ishiyama, M.D. ${ }^{2}$
}

\section{ABSTRACT}

In the last 10 years, there has been an emergence of reports related to opioid-induced sudden sensorineural hearing loss (SSNHL). The underlying pathology is not completely understood, and the mechanism(s) of action of these drugs in the inner ear remains to be determined. Reports of SSNHL due to the abuse of opioid peptides and other drugs suggest that the opioid system in the inner ear is affected. The reversible or irreversible effect on auditory function depends on the type of drug used and several other factors, including duration and time of exposure as well as the health status of drug users. Abuse of hydrocodone + acetaminophen (Vicodin ${ }^{\circledR}$ hydrocodone/paracetamol; Abbott Laboratories, Worcester, MA) has induced permanent hearing loss in several individuals. In contrast, abuse of heroin-induced hearing loss that was sometimes reversible. The widespread expression and physiological action of endogenous peptide opioids and their receptors in the inner ear suggests that pharmacological treatment for druginduced hearing loss is possible. The present study reviews the basic concepts of opioids and their receptors, provides clinical examples of hearing loss mediated by opioids and related drugs, reviews experimental evidence of the presence of opioids and their receptors in the inner ear (animal models and human studies), and describes the cellular targets affected by opioids and other recreational drugs.

KEYWORDS: Human cochlea, opioids receptors, hydrocodone, heroin, hearing loss

Learning Outcomes: As a result of this activity, the participant will be able to (1) identify the recreational drugs that cause sudden sensorineural hearing loss, (2) describe the possible sites and mechanism of action of these drugs in the inner ear, (3) differentiate between the types of recreational drugs that cause permanent or temporary hearing loss, (4) describe the treatments that clinicians have used when hearing loss is caused by opioids and other drugs.

${ }^{1}$ Department of Head and Neck Surgery; ${ }^{2}$ Department of Neurology, "David Geffen" School of Medicine at UCLA, Los Angeles, California.

Address for correspondence and reprint requests: Ivan A. Lopez, Ph.D., Department of Head and Neck Surgery, David Geffen School of Medicine at UCLA, Room 35-64 Rehabilitation Center, 1000 Veteran Avenue, Los Angeles CA 90095 (e-mail: ilopez@ucla.edu).
Proceedings of the 5th International NCRAR Conference-Expanding Our Horizons: Medical Conditions and Audiology; Guest Editors, Robert L. Folmer, Ph.D., and Gabrielle H. Saunders, Ph.D.

Semin Hear 2012;33:251-260. Copyright (C) 2012 by Thieme Medical Publishers, Inc., 333 Seventh Avenue, New York, NY 10001, USA. Tel: +1(212) 584-4662. DOI: http://dx.doi.org/10.1055/s-0032-1315724. ISSN 0734-0451. 
$\mathrm{O}_{\text {pioids are medications that relieve mod- }}$ erate and severe pain. ${ }^{1}$ These drugs are either naturally occurring or synthetic/semisynthetic chemicals that bind opioid receptors. ${ }^{2}$ The term opioid refers to a mixture of alkaloids such as morphine or codeine. Medications included within this class are hydrocodone, oxycodone, morphine, codeine, and related drugs. ${ }^{3}$ Ancient Egyptian medical records reported the use of opium for pain relief several millennia ago. ${ }^{4}$

The prevalence of abuse and addiction to opioids has fostered consternation among clinicians, law enforcement agencies, and policy makers. According to $\mathrm{Ho}$ et $\mathrm{al},{ }^{5}$ the World Health Organization estimated there are 185 million users of illicit drugs, 1.3 billion tobacco smokers, and 2 billion alcohol users worldwide. The National Institute on Drug Abuse (NIDA) reports that prescription medication used to treat pain, attention deficit disorders, and anxiety are being abused at a rate second only to marijuana among illicit drug users. NIDA's Monitoring the Future survey found that 1 in 12 high school seniors reported past year nonmedical use of the prescription pain reliever Vicodin ${ }^{\circledR}$ (Vicodin ${ }^{\circledR}$ hydrocodone/paracetamol; Abbott Laboratories, Worcester, MA) in 2010, and 1 in 20 reported abuse of OxyCon$\operatorname{tin}^{\mathbb{R}}$ (oxycodone hydrochloride; Purdue Pharma, Stamford, CT). In 2007, the number of overdose deaths in the United States from prescription opioids outnumbered deaths from heroin and cocaine combined. ${ }^{6}$

Effects of opioid use include dizziness, nausea, vomiting, drowsiness, and euphoria. ${ }^{4}$ Opioid abuse can cause severe respiratory depression and death. ${ }^{7}$ Sudden sensorineural hearing loss (SSNHL) also is beginning to be recognized as an adverse side effect of opioid abuse. In the past 10 years, there has been an emergence of reports related to opioid-induced sensorineural hearing loss. ${ }^{8}$ The underlying pathophysiology of this auditory dysfunction is not well understood. The present study reviews the basic concepts of opioids and their receptors, provides clinical examples of SSNHL mediated by opioids and related drugs, reviews experimental evidence of the presence of opioids and their receptors in the inner ear (animal models and human studies), and de- scribes the possible pathophysiological mechanisms of action of opioids in the inner ear.

\section{ENDOGENOUS OPIOIDS AND THEIR RECEPTORS}

Opioid receptors and their endogenous peptide ligands are largely distributed through the central nervous system and peripheral tissues. The opioid system plays a very important role in several physiological responses including nociception, emotional behavior, learning and memory, and regulation of reward circuits. ${ }^{7}$ The endogenous opioid peptides are mainly derived from four precursors: (1) proopiomelanocortin generates $\beta$-endorphin; (2) proenkephalin produces met-enkephalin, leu-enkephalin, met-enkephalin RGL, and met-enkephalin RF; (3) prodynorphin produces several dynorphins and neoendorphins; and (4) prepro-OFQ/ $\mathrm{N}$ produces orphanin $\mathrm{FQ} /$ nociceptin. 4

Opioid receptors belong to the large superfamily of seven transmembrane $G$ protein-coupled receptors. ${ }^{9}$ Pharmacological and molecular cloning studies have clearly established three classic types of opioid receptors: mu-opioid peptide receptor (MOP) or mu-opioid receptor (MOR) (= mu for morphine), kappa-opioid peptide receptor (KOP) or kappa-opioid receptor (KOR) (= kappa for ketocyclazocine), and delta-opioid peptide receptor (DOP) or deltaopioid receptor (DOR) (= delta for [vas] deferens). Nociceptin opioid receptor (NOP) (ORL-1, orphanin FQ/nociceptin receptor $(\mathrm{OFQ} / \mathrm{N}))$ is the fourth type of opioid receptor. ${ }^{9}$ Opioid receptors are activated by endogenously produced opioid peptides or exogenously administered opiated compounds (e.g., morphine, heroin, oxycodone).

All opioid receptors are involved in major opioid actions, including analgesia, reward, and the development of analgesic tolerance and physical dependence. ${ }^{9}$ Most clinically used opioids for analgesia are either nonselective opioid agonists or selective MOR agonists. The analgesic efficacy of currently used opioid analgesics is limited due to their tendency to cause analgesic tolerance, physical dependence, and other undesiderable side effects after 
prolonged and repeated use. ${ }^{1}$ The Drug Enforcement Agency classifies opioids into five schedules (I to V) of controlled drugs or common medications. As revised by Trescot et $\mathrm{al}^{4}{ }^{4}$ there are four chemical classes of opioids: (1) Phenanthrenes are the prototypical opioids. The presence of a 6-hydroxyl group in their structure may be associated with a higher incidence of nausea and hallucinations for this class. For example, morphine and codeine (both with 6-hydroxyl groups) are associated with more nausea than hydromorphone, oxymorphone, and oxycodone (which do not have 6-hydroxyl group). Opioids in this group include morphine codeine, hydromorphone, levorphanol, oxycodone, hydrocodone, oxymorphone, buprenorphine, nalbuphine, and butorphanol. (2) Benzomorphans have only pentazocine as a member of this class and are associated with a high incidence of dysphoria. (3) Phenylpiperidines include fentanyl, alfentanil, sufentanil, and meperidine; fentanyl has the highest affinity for MOR receptors. (4) Diphenylheptanes include propoxyphene and methadone. Tramadol does not fit into these four standard opioid classes. A unique analgesic, tramadol is an atypical opioid, a 4-phenyl-piperidine analogue of codeine, with partial MOR agonist activity in addition to central gamma-aminobutyric acid (GABA), catecholamine, and serotonergic activities. Opioids can further be classified by their actions: agonists, agonist/antagonists, or partial agonists, ${ }^{4}$ descriptions related to their effects on receptors.

\section{ANATOMY OF THE COCHLEA}

A review of cochlear anatomy is provided here in advance of a discussion of the mechanisms and actions of endogenous and exogenous opioids in the inner ear. The organ of Corti sits upon the basilar membrane within the fluid filled duct of the cochlea. Different cell types in the organ of Corti include the sensory cells (inner and outer hair cells) and several types of supporting cells. ${ }^{10}$

\section{The Afferent System}

Hearing requires an optimal innervation of the sensory hair cells, which transduce the acoustic signal. ${ }^{11}$ The pattern of innervation of the inner and outer hair cells in the organ of Corti is quite different. The primary afferent innervation is subdivided into at least two systems conveying sound information from the cochlea to the central nervous system: (1) thick myelinated fibers originating from type I spiral ganglion neurons (comprising 95\% of the cells found in the spiral ganglion) innervate inner hair cells and represent the principal encoding of the auditory signal; (2) thin unmyelinated fibers originating from type II ganglion cells innervate outer hair cells. Type II spiral ganglion neurons form "en passant" contacts with the outer hair cells and represent 5 to $10 \%$ of the total neuronal population. ${ }^{11}$ It is suggested that these innervations provide integrated afferent feedback loop and amplify both cochlear sensitivity and frequency discrimination. ${ }^{11,12}$

\section{Efferent Innervation}

Efferent fibers originating from the brain stem modulate neurotransmission of inner hair cells, either postsynaptically through synapses with afferent dendrites of primary afferent neurons or presynaptically through synapses directly onto the hair cells. ${ }^{12,13}$ Efferent innervation to the cochlea is subdivided into two systems: The lateral olivocochlear efferents (LOC) form axodendritic synapses with radial afferent fibers beneath the inner hair cells, and medial olivocochlear efferents form axosomatic synapses directly with outer hair cells. The efferent innervation is less pronounced in the human cochlea than in most animals. ${ }^{13,14}$

\section{Cochlear Vasculature}

The cochlea is a highly metabolically active structure with abundant vasculature that allows efficient delivery of nutrients, oxygen, and drugs to cochlear cells. Consequently, cochlear cells are sensitive to reductions in blood flow. ${ }^{15}$ Certain regions of the cochlea (such as the stria vascularis) are rich in blood vessels and are thus extremely well irrigated by a complex network of veins/capillaries for the delivery of oxygen and nutrients.

The cochlea receives its main blood supply from the basilar artery via the anterior cerebellar 
artery and the spiral modiolar artery. ${ }^{16}$ Vasospasms/constriction of these arteries can cause ischemic stroke of the inner ear, leading to SSNHL. ${ }^{17}$

One of the major mechanisms for control of blood flow is via neural innervations that regulate vasodilation or constriction. The mammalian auditory periphery receives a rich adrenergic innervation from the sympathetic nervous system, specifically from the stellate and superior cervical ganglia. ${ }^{18}$ Several neuropeptides are expressed in the innervations of the cochlear vasculature: calcitonin gene-related peptide (CGRP), vasoactive intestinal peptide (VIP), neuropeptide $\mathrm{Y}$ (NPY), substance $\mathrm{P}$, and nitric oxide synthase. A study by Wangemann and Wonnerberger ${ }^{19}$ demonstrated that cochlear blood flow is under the control of the sympathetic nervous system, and sympathetic nerve fibers have been identified along the basilar artery, the anterior inferior cerebellar artery, and the spiral modiolar artery.

\section{NEUROTRANSMITTERS AND NEUROPEPTIDES IN THE INNER EAR}

The activity of synapses between inner hair cells and type I afferent dendrites of the auditory nerve is modulated by LOC efferent fibers. ${ }^{12,14}$ These LOC efferents arise from the lateral cells of the superior olivary complex and radiate to the ipsilateral cochlea, terminating beneath the inner hair cells. ${ }^{12,20}$ Several neurotransmitters, including acetylcholine (ACh), GABA, serotonin, a variety of neuropeptides and dopamine, were identified as possible modulators of inner hair cell/auditory nerve synapses. ${ }^{21}$

\section{Afferent Neurotransmitters}

Evidence suggests that the main inner hair cell (afferent) neurotransmitter is an excitatory amino acid: glutamate. The presence and activity of glutamate, N-Methyl-D-aspartic acid (NMDA) receptors, 2-amino-3-(5methyl-3-oxo-1,2-oxazol-4-yl)propanoic acid (kainate/AMPA)-type glutamate receptor and glutamate transporters within the cochlea has been studied extensively. ${ }^{22,23}$ Because inner ear spiral ganglia synapses are susceptible to excitotoxicity, perfusion of glutamate or glu- tamate agonists results in degeneration of spiral ganglia neurons. For example, acoustic trauma results in damage to inner hair cell/ spiral ganglia synapses due to glutamate excitotoxicity, and inhibition of glutamate reuptake exacerbates cochlear damage from exposure to loud noise. ${ }^{24}$

\section{Efferent Neurotransmitters}

Numerous studies have documented ACh, GABA, CGRP, and enkephalins as efferent neurotransmitters in the cochlea. ${ }^{13} \mathrm{ACh}$ is the main efferent excitatory neurotransmitter, and GABA, CGRP, and enkephalins are involved in inhibitory regulation of neural transmission. The presence and activity of dopamine and its receptors in efferent cochlear neurotransmission is important given that dopamine receptors interact with opioid receptors in other systems. ${ }^{24}$ Moreover, recent studies have implicated dopamine in a neuroprotective role for the cochlea ${ }^{25}$ because dopamine mediates neural transmission between LOC efferent terminals and the dendrites of afferent auditory neurons. ${ }^{15,24}$

The functional importance of dopamine has been highlighted by observations that dopamine has a protective effect on the inner hair cell-afferent nerve synapses during ischemia or acoustic trauma by attenuating the postsynaptic effects of glutamate overstimulation. ${ }^{25}$ Dopaminergic neurons can be activated by opioids, cannabis, alcohol, and nicotine. The facilitation of dopamine release from presynaptic neurons or inhibition of its reuptake can be mediated by cocaine and amphetamines. ${ }^{26}$

\section{OPIOIDS AND OPIOID RECEPTORS IN THE INNER EAR}

Opioid receptors function in neuronal systems and local networks involved in the initiation of drug action and the subsequent development of adaptations in repeated drug use. ${ }^{27}$ In 1981, Fex and Altschuler ${ }^{28}$ demonstrated the existence of enkephalin-like immunoreactivity in the organ of Corti of the guinea pig and cat. There is a growing body of evidence that opioid neuropeptides participate in synaptic processing in hair cell systems. ${ }^{29,30}$ 
Studies on the distribution of opioid receptors in the auditory and vestibular periphery have been conducted in guinea pig and rat models. ${ }^{31-34}$ Immunocytochemistry, Western blot, and reverse-transcription polymerase chain reaction (RT-PCR) methods have shown the expression of all four known opioid receptor subtypes (MOR, DOR, KOR, ORL) in the cochlea. At the cellular level, MOR receptors were detected in the spiral ganglia neurons only, whereas DOR and KOR receptors were detected in inner and outer hair cells, interdental cells, and the spiral ganglia neurons. ${ }^{31-33} \mathrm{MOR}$ also has been detected in the vestibular periphery of the rat in calyceal and afferent-like terminals. ${ }^{34}$ Orphanin/FQ peptide (ORL-1 ligand) has been detected in the rat cochlea. ${ }^{35}$

Studies of MOR receptor-immunoreactivity and in situ hybridization have been made in the mouse $^{36}$ and human cochlea and vestibule in our laboratory. In the mouse cochlea, MOR is present in hair cells and spiral ganglia neurons, and in the human cochlea, MOR immunoreactivity and mRNA was detected in spiral ganglia neurons. In the vestibular sensory epithelia, MOR is located in the calyceal terminals and hair cells.

\section{PHYSIOLOGY OF OPIOID RECEPTORS IN THE INNER EAR}

The functionality of opioid receptors in the inner ear has been studied in several animal models ${ }^{37-41}$ and the following results were reported. Opioid drug effects on auditory evoked potentials suggest a role of lateral olivocochlear dynorphins in auditory func$\operatorname{tion}^{37}$; opioid receptors inhibit the adenylate cyclase in guinea pig cochleas ${ }^{38}$; opioid receptors mediate a postsynaptic facilitation and a presynaptic inhibition at the afferent synapse of axolotl vestibular hair cells ${ }^{39}$; the $\alpha 9 / \alpha 10$-containing nicotinic $\mathrm{ACh}$ receptor is directly modulated by opioid peptides; two neuropeptides (endomorphin-1 and dynorphin B) are efferent cotransmitters in the inner ear. ${ }^{40}$ The expression of the four opioid receptors, endogenous opioid peptides, and the physiologic response in the inner ear of animal models and in humans suggest that synthetic opioids may affect the homeostasis of the inner ear.

\section{SSNHL FOLLOWING OPIOID ABUSE}

SSNHL is characterized by the idiopathic loss of hearing either unilaterally or bilaterally that can develop over minutes, hours, or days. It can be triggered by mechanical cochlear injury, fluctuations of blood flow within the cochlea, viral infection, and autoimmune disorders. Opioid-induced SSNHL has been documented in several human case reports that are summarized later. The finding that opioids affect the excitability of the inner ear may explain why abuse of diverse drugs, such as heroin and hydrocodone, can produce significant alterations in hearing and balance. ${ }^{41}$ Soto and $\mathrm{Vega}^{41}$ reported a case of a Ménière's-like syndrome after a patient used epidural morphine. The specific mechanism(s) of action of opioids on different structures within the auditory system remains to be determined. The reversible or irreversible effect depends on the type of drug and several other factors, including duration and time of exposure as well as the health status of drug users. Clinical and research evidence suggests that pharmacological treatment of opioid-related auditory dysfunction is possible.

\section{Hydrocodone and SSNHL}

Codeine is an alkaloid derived from the opium poppy, and hydrocodone is a semisynthetic codeine derivative. Hydrocodone is effective as an antitussive and narcotic analgesic and is the most widely prescribed opioid in the United States. The combination of hydrocodone and acetaminophen (Vicodin) is prescribed for relief of acute and chronic pain. ${ }^{42}$ Reactions to this medication include dizziness, nausea, vomiting, drowsiness, and euphoria. There are several reports linking hydrocodone abuse and patients' subsequent development of SSNHL. ${ }^{42-46} \mathrm{Ho}$ et $\mathrm{al}^{42}$ reported on five patients (aged 28 to 57 years) with a chief complaint of progressive hearing loss after hydrocodone abuse. The patients' hydrocodone consumption varied from 10 to $300 \mathrm{mg} / \mathrm{d}$, and the duration of hydrocodone use prior to hearing loss varied from 1 month to 5 years. Audiograms recorded soon after hospital admission showed moderate hearing loss, but this progressed to profound hearing loss in all of these cases. Cessation of 
hydrocodone use and treatment with corticosteroids resulted in no improvement in hearing. Because the hearing loss was irreversible, all patients eventually underwent cochlear implantation.

Oh et $\mathrm{al}^{43}$ reported on two young patients who ingested high doses of Vicodin. The patients used Vicodin for 3 and 9 years, respectively, and both experienced hearing loss that progressed to profound levels bilaterally. These patients did not respond to treatment with high doses of oral prednisone, but their vestibular system was unaffected.

Friedman et $\mathrm{al}^{44}$ reported progressive SSNHL in 12 patients who abused Vicodin. Ten of these patients developed profound hearing loss over time. Although the vestibular system was relatively spared in 10 of the 12 patients, two patients did exhibit vestibular dysfunction. In all of these reports, ${ }^{42-45}$ damage to the auditory system caused by hydrocodone appeared to be irreversible. Inherent differences in auditory and vestibular effects exhibited by individuals who abuse hydrocodone are likely the result of variations in drug metabolism, drug transport proteins, receptors, or genetic susceptibility.

Heroin, Cocaine, Morphine, and SSNHL There are several reports of reversible SSNHL after heroin abuse. ${ }^{47-51}$ Schrock et $\mathrm{al}^{51}$ reported SSNHL in a 23-year-old man with a 2-year history of heroin abuse $(2 \mathrm{~g} / \mathrm{d})$. The patient first noticed hearing loss after 2 months of heroin abstinence. Audiometry conducted at that time revealed bilateral sensorineural deafness. The patient was treated with $250 \mathrm{mg}$ prednisolone (corticoids) and pentoxifylline (which improves blood circulation), and within 3 days the patient reported a significant improvement in hearing. However, the posttreatment audiogram showed symmetric high-frequency sensorineural hearing loss, which was an improvement over the pretreatment condition.

Ishiyama et $\mathrm{al}^{47}$ described another case of profound reversible hearing loss and vestibular dysfunction after a patient injected "black tar heroin." The patient had a 4-year history of heroin abuse $(1 \mathrm{~g} / \mathrm{d})$ and also had been on oral methadone maintenance. For 3 weeks prior to presentation, the patient had been completely abstinent from heroin and methadone. He then relapsed, injected $250 \mathrm{mg}$ of heroin, and was unconscious for 20 minutes. Upon awakening, the patient reported profound hearing loss, ear fullness, loud bilateral tinnitus, and severe vestibulopathy. Three months later, his hearing and vestibular function normalized. Two other reports of bilateral SSNHL after heroin injection $^{49,50}$ revealed similar clinical stories. The onset of bilateral deafness following heroin relapse may indicate a resensitization of a tolerized opioid system or possible hypersensitization of the system secondary to withdrawal. ${ }^{47}$

Stenner et $\mathrm{al}^{52}$ reported one case of bilateral severe SSNHL (with no tinnitus or vertigo) in a 26-year-old patient after cocaine abuse (intravenous twice, $50 \mathrm{mg} / \mathrm{mL}$ ). Ear, nose, and throat examination and tympanograms were normal for both ears. Therapy was initiated with intravenous infusions of sodium chloride (0.9\%), prednisolone in decreasing doses, and pentoxifylline. The following day, the patient reported steady improvement of hearing. On the third day, the audiogram showed normal hearing bilaterally.

There are a few reports of auditory dysfunction following the abuse of heroin in combination with alcohol or other drugs. For example, Antonopoulos et $\mathrm{al}^{53}$ reported a case of a 27-year-old man with a history of untreated hepatitis $\mathrm{C}$ and heroin abuse. The comatose patient was admitted to the hospital after consuming alcohol and snorting heroin. The patient regained consciousness 16 hours later and complained of a sudden reduction of hearing in both ears. The patient received treatment with prednisolone and magnesium for 15 days. Three days after treatment began, the audiogram showed slight improvements in hearing; 1 month later, there was complete restoration of the patient's hearing.

According to case studies, the combination of heroin and cocaine in the form of "speedballing" can cause mild to moderate bilateral SSNHL, ${ }^{54}$ and polysubstance abuse (heroin, benzodiazepine, alcohol, crack smoked, and cocaine) can result in moderately severe SSNHL. ${ }^{55}$ However, Grimmer et $\mathrm{al}^{56}$ concluded that newborns of opiate-addicted mothers are not at increased risk for early onset hearing loss. 


\section{Methadone, Propoxyphene Hydrochloride, and Amphetamines}

Methadone is a synthetic opioid that is used as an analgesic and as a maintenance antiaddictive medication for patients with opioid dependency. Unfortunately, methadone overdose also can cause SSNHL. ${ }^{57,58}$ Christenson and Marjal ${ }^{58}$ reported two cases of sudden SSNHL after methadone overdose, although the hearing loss in both patients reversed completely within 24 hours. Abuse of the synthetic opioid propoxyphene hydrochloride, an analgesic (trade names: Darvon, Darvocet (Xanodyne Pharmaceutical, Inc., Newport, KY)) also can lead to permanent SSNHL. ${ }^{5-61}$ Finally, Iqbal ${ }^{62,63}$ reported hearing loss in amphetamine-dependent inpatients. In most of these cases, patients' hearing recovered between 4 and 10 days after cessation of amphetamine use.

\section{MECHANISMS OF AUDITORY DYSFUNCTION FOLLOWING DRUG ABUSE}

The pathogenesis of hearing loss after recreational drug intake remains obscure, although various mechanisms have been proposed, including cochlear anoxia, ototoxicity, and auditory nerve damage. ${ }^{47-54}$ Reduced blood flow also can contribute to SSNHL. For example, cocaine's sympathomimetic properties are known to cause vasoconstriction, which can cause hearing loss in some cases, especially in high-dose users. In most of the cases of SSNHL described in this article, the patients' high frequencies were affected more severely than low frequencies, suggesting that the primary site of damage is the basal region of the cochlea.

A direct toxic effect of heroin on the cochlea was proposed by Polpathapee et al. ${ }^{64}$ As an MOR agonist, heroin could bind to opioid receptors in the cochlea and provoke a down-regulation of auditory sensitivity ${ }^{51}$ or a resensitization of a tolerized opioid system and a prolonged hypersensitization of the system secondary to withdrawal. ${ }^{47}$ SSNHL also might be caused by the ototoxicity of heroin-adulterant additives, such as quinine, that damages outer hair cells of the cochlea. Kortequee et $\mathrm{al}^{48}$ reported SSNHL following intracarotid injection of heroin, which was attributed to induced vasospasm or vasculitis. Iqbal ${ }^{62}$ and other authors proposed that recoverable types of hearing loss in drug and alcohol users may be attributed to temporal lobe ischemia and hypoperfusion of the vestibulocochlear system. ${ }^{65,66}$

\section{CONCLUSIONS}

Reports of SSNHL due to the abuse of opioid peptides and other drugs suggest that the opioid system in the inner ear is affected by these substances. However, the specific mechanism(s) of action of these drugs remains to be determined. Their reversible or irreversible effects on auditory functions depend on the type of drug used and several other factors, including duration and time of exposure as well as the health status of drug users. Abuse of high doses of hydrocodone + acetaminophen (Vicodin) tends to induce permanent hearing loss. In contrast, abuse of heroin, methadone, or amphetamines seems to induce a more reversible hearing loss.

Clinical reports suggest that pharmacological treatment of auditory dysfunction caused by drug abuse is possible in some cases. Therefore, it is important to increase clinicians' awareness of the possibility that patients who present with SSNHL might have hearing loss as a result of drug abuse. Asking such patients about their recent history of prescription and recreational drug use should become routine.

The lower frequencies are relatively spared in most cases of opiate-associated hearing loss, suggesting that ototoxicity or other mechanisms of damage occur primarily at the base of the cochlea. There is need for research using animal models to investigate the effects of recreational and prescription drugs on hearing. Gene expression analysis and the use of proteomic techniques also could be used to study the mechanisms and pathophysiology of SSNHL after drug abuse. Finally, efforts should be made to study and correlate changes in the central auditory and vestibular systems that occur after drug abuse.

\section{ACKNOWLEDGMENT}

This work was supported by NIH/NIDCD grant 5U24 DC 008635. 
NOTE

Presented at the Biennial NCRAR International Conference, October 12 to 14,2011 , Portland, Oregon.

\section{REFERENCES}

1. Bie B, Pan ZZ. Trafficking of central opioid receptors and descending pain inhibition. Mol Pain 2007;3:27

2. Zuo Z. The role of opioid receptor internalization and b-arrestins in the development of opioid tolerance. Anesth Analg 2005;10:728-734

3. Meyer MR, Maurer HH. Absorption, distribution, metabolism and excretion pharmacogenomics of drugs of abuse. Pharmacogenomics 2011;12: 215-233

4. Trescot AM, Datta S, Lee M, Hansen H. Opioid pharmacology. Pain Physician 2008;11:S133-153

5. Ho T, Vrabec JT, Burton AW. Hydrocodone use and sensorineural hearing loss. Pain Physician 2007;10:467-472

6. National Institute on Drug Abuse. Prescription Drugs: Abuse and Addiction. U.S. Department of Health and Human Services, National Institutes of Health/National Institute on Drug Abuse, Baltimore, MD. NIH Publication number 11-4881, 2011

7. Trigo JM, Martin-García E, Berrendero F, Robledo P, Maldonado R. The endogenous opioid system: a common substrate in drug addiction. Drug Alcohol Depend 2010;108:183-194

8. Schweitzer VG, Darrat I, Stach BA, Gray E. Sudden bilateral sensorineural hearing loss following polysubstance narcotic overdose. J Am Acad Audiol 2011;22:208-214

9. Waldhoer M, Bartlett SE, Whistler JL. Opioid receptors. Annu Rev Biochem 2004;73:953-990

10. Slepecky N. Structure of the mammalian cochlea. In: Dallos P, Popper AN, Fay RR, eds. The Cochlea. Springer Handbook of Auditory Research. New York, NY: Springer; 1996:44-129

11. Defourny J, Lallemend F, Malgrange B. Structure and development of cochlear afferent innervations in mammals. Am J Physiol Cell Physiol 2011;301: C750-C761

12. Guinan JJ Jr. Cochlear efferent innervation and function. Curr Opin Otolaryngol Head Neck Surg 2010;18:447-453

13. Schrott-Fischer A, Kammen-Jolly K, Scholtz A, Rask-Andersen H, Glueckert R, Eybalin M. Efferent neurotransmitters in the human cochlea and vestibule. Acta Otolaryngol 2007;127:13-19

14. Elgoyhen AB, Katz E. The efferent medial olivocochlear-hair cell synapse. J Physiol Paris 2011; July 6 (Epub ahead of print)
15. Halmos G, Doleviczényi Z, Répássy G, et al. D2 autoreceptor inhibition reveals oxygen-glucose deprivation-induced release of dopamine in guinea-pig cochlea. Neuroscience 2005;132:801-809

16. Lyon MJ, Payman RN. Comparison of the vascular innervation of the rat cochlea and vestibular system. Hear Res 2000;141:189-198

17. Scherer EQ Arnold W, Wangemann P. Pharmacological reversal of endothelin-1 mediated constriction of the spiral modiolar artery: a potential new treatment for sudden sensorineural hearing loss. BMC Ear Nose Throat Disord 2005;5:10

18. Maison SF, Le M, Larsen E, et al. Mice lacking adrenergic signaling have normal cochlear responses and normal resistance to acoustic injury but enhanced susceptibility to middle-ear infection. J Assoc Res Otolaryngol 2010;11:449-461

19. Wangemann P, Wonneberger K. Neurogenic regulation of cochlear blood flow occurs along the basilar artery, the anterior inferior cerebellar artery and at branch points of the spiral modiolar artery. Hear Res 2005;209:91-96

20. Guinan JJ Jr. Olivocochlear efferents: anatomy, physiology, function, and the measurement of efferent effects in humans. Ear Hear 2006; 27:589-607

21. Puel JL. Chemical synaptic transmission in the cochlea. Prog Neurobiol 1995;47:449-476

22. Usami SI, Takumi Y, Matsubara A, Fujita S, Ottersen OP. Neurotransmission in the vestibular endorgans-glutamatergic transmission in the afferent synapses of hair cells. Biol Sci Space 2001; $15: 367-370$

23. Hakuba N, Koga K, Gyo K, Usami SI, Tanaka K. Exacerbation of noise-induced hearing loss in mice lacking the glutamate transporter GLAST. J Neurosci 2000;20:8750-8753

24. Darrow KN, Simons EJ, Dodds L, Liberman MC. Dopaminergic innervation of the mouse inner ear: evidence for a separate cytochemical group of cochlear efferent fibers. J Comp Neurol 2006; 498:403-414

25. Lendvai B, Halmos GB, Polony G, et al. Chemical neuroprotection in the cochlea: the modulation of dopamine release from lateral olivocochlear efferents. Neurochem Int 2011;59:150-158

26. Ross S, Peselow E. Pharmacotherapy of addictive disorders. Clin Neuropharmacol 2009;32: 277-289

27. Williams JT, Christie MJ, Manzoni O. Cellular and synaptic adaptations mediating opioid dependence. Physiol Rev 2001;81:299-343

28. Fex J, Altschuler RA. Enkephalin-like immunoreactivity of olivocochlear nerve fibers in cochlea of guinea pig and cat. Proc Natl Acad Sci U S A 1981;78:1255-1259

29. Hoffman DW, Altschuler RA, Fex J. Highperformance liquid chromatographic identification 
of enkephalin-like peptides in the cochlea. Hear Res 1983;9:71-78

30. Eybalin M. Neurotransmitters and neuromodulators of the mammalian cochlea. Physiol Rev 1993;73:309-373

31. Phansuwan-Pujito P, Saleema L, Mukda S, et al. The opioid receptors in inner ear of different stages of postnatal rats. Hear Res 2003;184:1-10

32. Jongkamonwiwat N, Phansuwan-Pujito P, Sarapoke $\mathrm{P}$, et al. The presence of opioid receptors in rat inner ear. Hear Res 2003;181:85-93

33. Jongkamonwiwat $\mathrm{N}$, Phansuwan-Pujito $\mathrm{P}$, Casalotti SO, Forge A, Dodson H, Govitrapong P. The existence of opioid receptors in the cochlea of guinea pigs. Eur J Neurosci 2006;23:2701-2711

34. Popper P, Cristobal R, Wackym PA. Expression and distribution of $\mathrm{mu}$ opioid receptors in the inner ear of the rat. Neuroscience 2004;129:225-233

35. Kho ST, Lopez IA, Evans C, Ishiyama A, Ishiyama G. Immunolocalization of orphanin FQ in rat cochlea. Brain Res 2006;1113:146-152

36. Ishiyama G, Lopez IA, Ishiyama A, Evans CJ. Immunolocalization of $\mathrm{mu}$ and delta opioid receptors in the mouse cochlea. Paper presented at: 26th ARO Meeting, Daytona Beach, FL, Feb. 22-37. Abstract \# 1850; 2003

37. Sahley TL, Kalish RB, Musiek FE, Hoffman DW. Effects of opioid be drugs on auditory evoked potentials suggest a role of lateral olivocochlear dynorphins in auditory function. Hear Res 1991; 55:133-142

38. Eybalin M, Pujol R, Bockaert J. Opioid receptors inhibit the adenylate cyclase in guinea pig cochleas. Brain Res 1987;421:336-342

39. Vega R, Soto E. Opioid receptors mediate a postsynaptic facilitation and a presynaptic inhibition at the afferent synapse of axolotl vestibular hair cells. Neuroscience 2003;118:75-85

40. Lioudyno MI, Verbitsky M, Glowatzki E, et al. The alpha9/alpha10-containing nicotinic ACh receptor is directly modulated by opioid peptides, endomorphin-1, and dynorphin B, proposed efferent cotransmitters in the inner ear. Mol Cell Neurosci 2002;20:695-711

41. Soto E, Vega R. Neuropharmacology of vestibular system disorders. Curr Neuropharmacol 2010;8: $26-40$

42. Ho T, Vrabec JT, Burton AW. Hydrocodone use and sensorineural hearing loss. Pain Physician 2007;10:467-472

43. Oh AK, Ishiyama A, Baloh RW. Deafness associated with abuse of hydrocodone/acetaminophen. Neurology 2000;54:2345

44. Friedman RA, House JW, Luxford WM, Gherini S, Mills D. Profound hearing loss associated with hydrocodone/acetaminophen abuse. Am J Otol 2000;21:188-191
45. Rigby MH, Parnes LS. Profound hearing loss associated with oxycodone-acetaminophen abuse. J Otolaryngol Head Neck Surg 2008;37: E161-E162

46. Rawool V, Dluhy C. Auditory sensitivity in opiate addicts with and without a history of noise exposure. Noise Health 2011;13:356-363

47. Ishiyama A, Ishiyama G, Baloh RW, Evans CJ. Heroin-induced reversible profound deafness and vestibular dysfunction. Addiction 2001;96: 1363-1364

48. Kortequee S, Agada FO, Coatesworth AP. Sudden sensorineural hearing loss following intracarotid injection of heroin. Int J Clin Pract Suppl 2005;147:128-129

49. Mulch G, Handrock M. ["Sudden binaural deafness" after acute heroin intoxication (author's transl)]. Laryngol Rhinol Otol (Stuttg) 1979; 58:435-437

50. Polpathapee S, Tuchinda P, Chiwapong S. Sensorineural hearing loss in a heroin addict. J Med Assoc Thai 1984;67:57-60

51. Schrock A, Jakob M, Wirz S, Bootz F. Sudden sensorineural hearing loss after heroin injection. Eur Arch Otorhinolaryngol 2008;265:603-606

52. Stenner M, Stürmer K, Beutner D, Klussmann JP. Sudden bilateral sensorineural hearing loss after intravenous cocaine injection: a case report and review of the literature. Laryngoscope 2009;119: 2441-2443

53. Antonopoulos S, Balatsouras DG, Kanakaki S, Done A, Spiliopoulou C, Giannoulois G. Bilateral sudden sensorineural hearing loss caused by alcohol abuse and heroin sniffing. Auris Nasus Larynx 2012;39:305-309

54. Fowler CG, King JL. Sudden bilateral sensorineural hearing loss following speedballing. J Am Acad Audiol 2008;19:461-464

55. Schweitzer VG, Darrat I, Stach BA, Gray E. Sudden bilateral sensorineural hearing loss following polysubstance narcotic overdose. J Am Acad Audiol 2011;22:208-214

56. Grimmer I, Bührer C, Aust G, Obladen M. Hearing in newborn infants of opiate-addicted mothers. Eur J Pediatr 1999;158:653-657

57. van Gaalen FA, Compier EA, Fogteloo AJ. Sudden hearing loss after a methadone overdose. Eur Arch Otorhinolaryngol 2009;266:773-774

58. Christenson BJ, Marjala AR. Two cases of sudden sensorineural hearing loss after methadone overdose. Ann Pharmacother 2010;44:207-210

59. Lupin AJ, Harley CH. Letter: Inner ear damage related to propoxyphene ingestion. Can Med Assoc J 1976;114:596

60. Harell M, Shea JJ, Emmett JR. Total deafness with chronic propoxyphene abuse. Laryngoscope 1978; 88(9 Pt 1):1518-1521 
61. Ramsay BC. Complete nerve deafness after abuse of co-proxamol. Lancet 1991;338:446-447

62. Iqbal N. Recoverable hearing loss with amphetamines and other drugs. J Psychoactive Drugs 2004; 36:285-288

63. Iqbal N. Hearing loss in amphetamine users. J Psychoactive Drugs 2002;34:401-407

64. Polpathapee S, Tuchinda P, Chiwapong S. Sensorineural hearing loss in a heroin addict. J Med Assoc Thai 1984;67:57-60
65. Ciorba A, Bovo R, Prosser S, Martini A. Considerations on the physiopathological mechanism of inner ear damage induced by intravenous cocaine abuse: cues from a case report. Auris Nasus Larynx 2009;36:213-217

66. Nicoucar K, Sakbani K, Vukanovic S, Guyot JP. Intralabyrinthine haemorrhage following cocaine consumption. Acta Otolaryngol 2005;125: 899-901 